\title{
Correspondence
}

\section{Similarity of drug labels predisposes to drug errors}

To the Editor:

We report an anaesthetic accident related to the problem of labelling of drug containers in anaesthesia. An 80yr-old man was scheduled for craniotomy for resection of a large meningioma. After the usual monitoring had been installed, anaesthesia was induced with sufentanil $150 \mu \mathrm{g}$, lidocaine $100 \mathrm{mg}$ and thiopentone $350 \mathrm{mg}$. Pancuronium $4 \mathrm{mg}$ and metocurine (Metubine ${ }^{\circledR}$ ) $10 \mathrm{mg}$ were administered over one minute for muscle relaxation. Arterial pressure then rapidly increased from $130 / 70$ to $220 /$ 95 and heart rate from 65 to $130 \mathrm{~min}^{-1}$. Hyperventilation by mask was increased, and this sympathomimetic response was controlled with intravenous labetalol but blood pressure and heart rate remained elevated for about 20 min. After five minutes of mask ventilation, only minimal muscle relaxation was apparent at train-of-four stimulation of the ulnar nerve. It was then realized that 5 $\mathrm{ml}(62.5 \mathrm{mg})$ of undiluted Dobutrex ${ }^{\circledR}$ solution had been administered instead of $10 \mathrm{mg}$ of Metubine ${ }^{\circledR}$. Additional muscle relaxant was adminstered and tracheal intubation was performed easily. Surgery proceeded without incident, lasting seven hours. Thirty minutes after arrival in the recovery room, after the tracheal tube had been removed, mental state was normal and neurological examination was comparable to the preoperative state. The electrocardiogram at $24 \mathrm{hr}$ post-op showed no change from before surgery. The postoperative period was uneventful and the patient was discharged on post-op day 22.

The subsequent inquiry revealed that the Dobutrex ${ }^{\circledR}$ vial had been placed in the location of metocurine in the drug tray of the anaesthesia cart during its filling by the pharmacy department. Dobutrex ${ }^{\circledR}$ is usually not present in our anaesthesia drug trays, but is stored in a different location in the operating room. Metubine $\left.{ }^{(}{ }^{(}\right)$ and Dobutrex ${ }^{\circ}$ are both manufactured by Eli Lilly Canada Inc. and are both presented in $20 \mathrm{ml}$ vials that look very similar. Except for the plastic cap, the colour of both vials is identical. The main difference is that the label of Metubine ${ }^{\circledR}$ reads horizontally while that of Dobutrex ${ }^{(\circledR)}$ reads vertically (Figure). Although anaesthetists should always read carefully the label before giving any drug, it seems imperative to us that metocurine and dobutamine

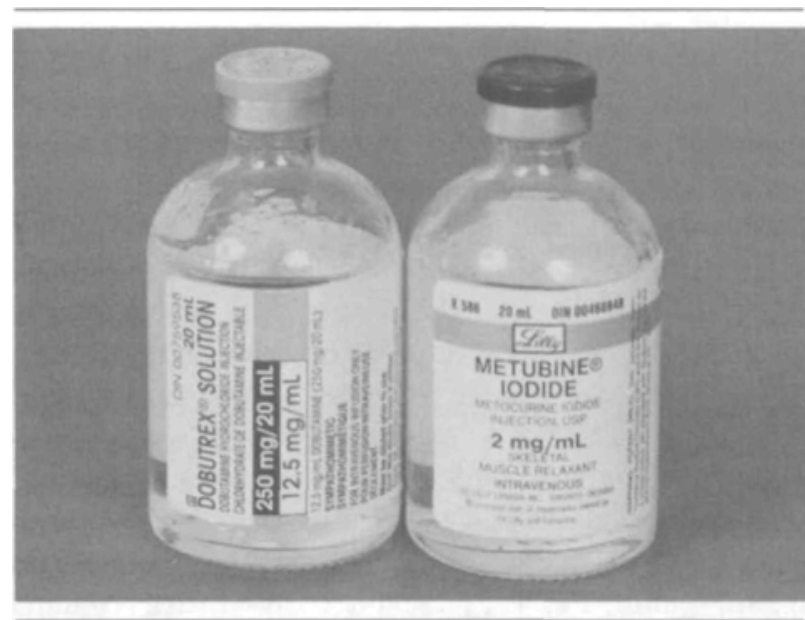

FIGURE Similarity between labels of Metubine ${ }^{\circledR}$ and Dobutrex ${ }^{\circledR}$

should be distinguishable at a glance. Anaesthetists are exposed to this kind of accident since drugs are commonly injected in rapid boluses. An accidental bolus administration of drugs like Dobutrex that requires dilution prior to its use may have lethal consequences. Fortunately this drug error was of no consequence to the patient. It could have been different had the patient suffered from coronary artery disease or from a ruptured intracranial aneurysm. This case primarily stresses the importance of reading carefully the label before injecting any drug. However, drug manufacturers should label their products in such a way that this kind of drug error has the least chance to occur.'

Martin R.Lessard MD FRCPC

Maryse Mathieu MD

Michel Fafard MD FRCPC

Département d'anesthésie

Hôpital de l'Enfant-Jésus

1401, $18^{\text {ième }}$ Rue Québec (Québec) G1J 1ZA

Fax: 418-649-5918

\section{REFERENCE}

1 Rendell-Baker $L$. Better labels will cut drug errors. Anaesthesia Patient Safety Foundation newsletter 1987; 2: 29-32.

(No response from Eli Lilly Canada to whom a copy of this letter was sent. Ed.) 